\title{
ОСОБЕННОСТИ МЕЖКОНФЕССИОНАЛЬНЫХ ОТНОШЕНИЙ В ПРИГРАНИЧНЫХ РЕГИОНАХ РОССИЙСКОЙ ФЕДЕРАЦИИ: ОБЗОР ПРИКЛАДНЫХ И ТЕОРЕТИЧЕСКИХ ИССЛЕДОВАНИЙ ${ }^{1}$
}

\author{
А.С. Качур \\ Алтайский государственный университет, Барнаул, Россия, \\ e-mail:kachur1991@yandex.ru
}

\section{DOI: 10.14258/ssi(2019)4-12}

Анализируются межконфессиональные отношения в Российской Федерации и ее приграничных регионах, особенности взаимодействия религиозных организаций и государства. Затрагиваются проблемы влияния религиозного фактора на распространение экстремистских настроений. Результаты социологического исследования, проведенного в приграничных регионах, свидетельствуют о том, что межнациональное и межконфессиональное согласие является важным фактором обеспечения социальной и национальной безопасности приграничных регионов и целостности Российской Федерации.

Ключевые слова: межконфессиональные отночения, межнациональные отношения, религия, миграџия, экстремизм, сочиильная безопасность.

\section{FEATURES OF THE INTERFAITH RELATIONS IN BORDER AREAS OF THE RUSSIAN FEDERATION: A REVIEW OF APPLIED OR THEORETICAL RESEARCHES}

\author{
A.S. Kachur \\ Altai State University, Barnaul, Russia, \\ e-mail: kachur1991@yandex.ru
}

\begin{abstract}
The article is devoted to studying the interfaith relations in the Russian Federation and its border areas, the peculiarities of interaction between religious organizations and the State. Issues of influence of a religious factor on distribution of extremist moods are discussed as well. The results of a sociological survey conducted
\end{abstract}

\footnotetext{
1 Публикация подготовлена в рамках выполнения гранта Президента Российской Федерации для государственной поддержки ведущих научных школ НШ-6535.2018.6 «Социальные риски и безопасность в условиях трансформации миграционных процессов в азиатском приграничье России» (2018-2019 гг.).
} 
in some Russian border regions indicate that interethnic and interfaith harmony is an important factor of ensuring social and national security and the integrity of the Russian Federation.

Keywords: interfaith relations, international relations, religion, migration, extremism, social safety.

\section{Введение}

Россия исторически является многонациональной и многоконфессиональной страной. С учетом проживания на территории Российской Федерации большого количества национальностей, различающихся по принадлежности к конфессиям, изучение проблем межконфессиональных отношений является очень важным и актуальным для нашей страны с точки зрения построения равноправных отношений во всех сферах жизнедеятельности общества.

Для более полного понимания данного процесса необходимо выделить и охарактеризовать основные понятия, связанные с ним. Согласно определению С.Г. Денисова, данному в работе «Особенности религиозной ситуации и межконфессиональных отношений в современном российском мегаполисе», «межконфессиональные отношения - это сложная система взаимоотношений людей, придерживающихся разных религиозных взглядов, принадлежащих к различным конфессиям» (Денисов, 2011). Конфессия, от латинского confessio, означает вероисповедание. Обычно термин «конфессия» применяют к одному из направлений в рамках отдельной религии. Религия, согласно философскому определению, — это форма общественного сознания, объясняющая мир посредством сверхъестественной силы (Бога). Сегодня существуют три мировые религии: христианство, ислам, буддизм (Кикель, Сороко, 2008). Взаимодействие между религиями и конфессиями составляет межконфессиональные отношения. Вместе с тем межконфессиональные отношения всегда развиваются в определенной социальной, экономической и политической ситуации. Стоит отметить, что согласно ст. 14 Конституции РФ ${ }^{1}$ наша страна является светским государством, в связи с этим «никакая религия не может устанавливаться в качестве государственной или обязательной. Религиозные объединения отделены от государства и равны перед законом». Таким образом, отношение к религии является личным делом каждого гражданина. Так обеспечивается свобода вероисповедания, что создает предпосылку создания свободного гражданского общества.

Межконфессиональные отношения всегда изучались с целью гармонизации общественной жизни, предотвращения дискриминации и регулирования конфликтов. Межконфессиональному взаимодействию, разным аспектам его проявления, факторам стабилизации и дестабилизации межконфессиональных отношений посвящены многочисленные работы западноевропейских и российских политологов, социологов, антропологов, политических и социальных психологов и конфликтологов.

1 Конституция Российской Федерации. URL: http://www.consultant.ru/document/cons_doc_ LAW_28399/. 
Отдельно следует отметить теоретическую позицию А.А. Нуруллаева, представившего в своих работах всестороннее рассмотрение проблематики межконфессиональных отношений, изучающее не только ее реалии, но и включающее прогноз развития, а также рекомендации по совершенствованию отношений между конфессиями, религиями и другими социальными институтами (Нуруллаев, 2006).

Проблемы религиозности и религиозной ситуации на региональном уровне освещены в работах Г.Л. Выдриной, Ю.В. Попкова, Е.А. Тюгашева (Ханты-Мансийский автономный округ - Югра), И.В. Симонова, Н.Г. Ярыгина (Нижегородская область), Ю.Ю. Синелиной (Ярославская область), О.М. Хомушку, Н.Г. Дубровского (Республика Тыва). В Волгоградской области вопросы религиозных организаций, межконфессиональных отношений, истоков и тенденций развития религиозной ситуации являются проблемными областями, интересными для изучения таких религиоведов, социологов, философов, историков, как О.Ю. Редькина, О.И. Сгибнева, Н.Н. Станкова, Е.О. Беликова. В Астраханской области изучением проблем межконфессиональных отношений в разное время занимались Л.С. Рубан, А.В. Сызранов.

Целый ряд работ посвящен проблемам взаимосвязи межнациональных и межконфессиональных отношений. Среди них книги и статьи Л.А. Баширова, Р.А. Лопаткина, А.В. Малашенко, С.В. Медведко. Специальные научные труды, посвященные рассмотрению новых угроз, связанных с религиозным фактором, и прежде всего с экспансией нетрадиционных для России религиозных форм, начали появляться на рубеже XX-XXI вв. Это работы А.Г. Никитиной, М.П. Мчедлова, А.А. Нуруллаева, Э.Г. Филимонова, Е.С. Элбакян, Н.А. Трофимчука, М.П. Свищева. Так, исследователи отмечают влияние процессов, происходящих в религиозном пространстве, на развитие межэтнических и межнациональных отношений.

Область изучения межконфессионального взаимодействия чрезвычайно широка: это особенности изменений внутри той или иной религиозной конфессии, в том числе тенденций в различных религиозных направлениях; соотношение традиционной и современной культур в отдельных конфессиях; проблемы границ межконфессионального пространства; роль религии в культурной дистанции; религиозные интересы и установки на межконфессиональное общение; межконфессиональные ориентации; толерантность и интолерантность; социальные и социально-психологические основы межконфессиональных конфликтов и т.д. Среди различных угроз социальной и национальной безопасности Российской Федерации на современном этапе многие авторы указывают на появление информационных, а также идеологических и в том числе религиозных угроз.

\section{Религия и социальная безопасность}

Этническая и конфессиональная ситуация в современной Российской Федерации и ее субъектах имеет динамичный и неустойчивый характер. На динамику межконфессиональных отношений оказывают влияние множество факторов, которые необходимо учитывать при их анализе. Так, среди факторов, влияющих на межконфессиональные отношения, следует отметить изменения этнодемографического состава населения, различное экономическое и социальное положение граждан, динамику отношения людей 
к религии в целом, работу отдельных религиозных организаций, политику государства в сфере национальных интересов, рост и усложнение миграционных потоков, появление большого количества трудовых мигрантов из иностранных государств, деятельность националистических и экстремистских движений, популяризацию этнической и религиозной неприязни через средства массовой информации и интернет. Все названные основания создают условия для возникновения новых межконфессиональных противоречий, социальной напряженности и конфликтов (Богатова, Карьгин, 2010).

Кроме того, в нашей стране эти факторы были дополнены сложными внутренними политическими процессами, связанными с распадом Советского Союза, трудным переходным периодом в становлении нового государства. Свой отпечаток наложили заметные различия в экономическом потенциале и уровне жизни населения отдельных регионов. В данный период произошла актуализация этнического и религиозного факторов, возросла их роль в формировании общественного сознания. Это способствовало нарастанию в обществе состояния нетерпимости, ведущего к обострению напряженности в межнациональных и межконфессиональных отношениях, повышающих риск конфликтов на этнической и религиозной почве и тем самым несущих угрозу политической стабильности общества и целостности российского государства (Ярулин, 2014).

Важным является тот факт, что после распада СССР многие субъекты Российской Федерации стали иметь статус приграничных, имея прямой выход к государственной границе. Происходящие в них процессы непосредственно или опосредованно воздействуют на состояние пограничной безопасности страны в целом. Постоянным фактором российской общественно-политической жизни является межэтническая и межконфессиональная напряженность (Ярулин, 2014).

Ее главным источником остается внешняя и внутренняя миграция: основные потоки внешней миграции шли из Центральной Азии и внутренней - с Северного Кавказа. Сохранению напряженности, безусловно, способствует отсутствие у государства выработанной миграционной политики и коррумпированность структур, занимающихся контролем миграционных потоков.

В ряде регионов напряженность в сфере межконфессиональных отношений носит систематический характер. Наиболее остро она проявляется в Москве, Республике Дагестан и Ханты-Мансийском автономном округе. В столице Российской Федерации, по мнению исследователей, это связано с большим количеством мигрантов, число которых превышает 2 млн чел.; в Дагестане это обусловлено распространением радикальных исламистских настроений. Что же касается Ханты-Мансийского автономного округа, то он попал в категорию кризисных территорий сравнительно недавно - 5-6 лет назад. Там, как и в Москве, устойчивость межэтнических и межконфессиональных столкновений объясняется быстрым ростом числа мусульман-мигрантов, что привело к изменению демографической ситуации. ${ }^{1}$

Сложная ситуация отмечается еще в 18 регионах России, в частности к ним относятся Астраханская, Волгоградская, Ростовская области, Республика Башкор-

1 ФСО определила регион с самыми напряженными межконфессиональными отношениями. URL: http://www.newsru.com/russia/25mar2016/fsosurvey.html. 
тостан, где отмечаются неоднократные одиночные и групповые конфликты на этноконфессиональной почве насильственного характера, а также без применения силы (Ярулин, 2014). ${ }^{1}$

В связи с развитием демократии и существенным расширением в постсоветский период свободы религии и вероисповедания характерная для российского общества поликонфессиональность еще больше возросла. В настоящее время по данным Федеральной службы государственной статистики в стране зарегистрировано более 30 тысяч религиозных организаций, объединивших более 70 конфессий, религиозных направлений и течений. Русская православная церковь представлена 18101 организацией, ислам - 5663, христиане веры евангельской - пятидесятники - 1171 организацией, Евангельские христиане-баптисты - 888, Евангельские христиане - 720, старообрядчество - 378 организациями, протестантизм - 119 , иудаизм - 269, буддизм - 265, римско-католическая церковь - 235 и др. ${ }^{2}$

На фоне глубоких перемен в экономической, политической и духовной сферах жизни общества, происходящих в нашей стране, интерес к религии резко возрос. Конфликтный и агрессивный характер межнациональных отношений, выраженный в общественных настроениях, влияет на безопасность общества в целом. В последнее время среди факторов, прямо или косвенно влияющих на состояние межнациональных отношений, исследователи отмечают религиозный фактор.

Отсутствие мер по нормализации взаимодействий в области социально-политических, экономических, этнических, религиозных отношений приводит к дестабилизации, проблемам социальной безопасности общества. Для Российской Федерации, как многонационального, многоконфессионального государства, особенно важно на уровне органов государственной и муниципальной власти осуществлять правильную, грамотную координацию мер, основанных на комплексе знаний в сфере регулирования межэтнических и межконфессиональных отношений, направленных на обеспечение в регионах страны и Российской Федерации в целом политической стабильности и правопорядка. В решении вопросов, связанных с проблемами межконфессиональных отношений, важным является понимание необходимости налаживания эффективной работы по профилактике и раннему предупреждению любых проявлений экстремизма.

В нашей стране данная проблема стала особенно актуальной в последние годы. Уровень опасности экстремизма на религиозной почве, заключающегося в разжигании ненависти в сфере межрелигиозных и межконфессиональных отношений, в регионах возрос. Одним из современных инструментов воздействия на общество для обострения этнической и межконфессиональной розни и совершения на ее основе преступлений, используемых экстремистами, является интернет. Особую опасность представляют международные экстремистские и террористические организации,

\footnotetext{
1 ФСО: Лучше всех межнациональными отношениями занимаются в Чечне, на последнем месте Москва. Национальный акцент: Медиа-проект Гильдии межэтнической журналистики, 2015. URL: http:// nazaccent.ru/content/14916-monitoring-luchshe-vsego-mezhnacionalnymi-otnosheniyami-zanimayutsya.html.

2 Государство, общественные организации. Федеральная служба государственной статистики. URL: http://www.gks.ru.
} 
преступная деятельность которых разными каналами распространяется по регионам нашей страны. В данных условиях молодежь является наиболее восприимчивой к радикальным идеям в силу своей неопытности, из-за отсутствия воспитательного наставничества со стороны родителей и общества.

Экстремизм в молодежной среде - одна из острых проблем современной России. В молодежной среде растет количество преступлений, повышается уровень насилия, в ней экстремизм имеет более организованный характер. По данным МВД Российской Федерации, сегодня в стране действуют около 150 экстремистских молодежных группировок, в деятельность которых вовлечены почти 10 тысяч человек.

Специфическая природа человека обусловлена неизбежным стремлением выйти за границы эмпирически доступного мира, обнаружить непостижимый смысл своего существования, обрести «духовную почву» в социальной реальности. Поэтому ставить религиозные организации в ряд других общественных организаций, таких как профсоюзы, спортивные общества и др., с правовой точки обоснованно, а вот с точки зрения природы сущности и предназначения церковной организации - понятно, что у нее другие цели и задачи, как в гражданском обществе, так и в межконфессиональном взаимодействии.

Фактор конфессиональной принадлежности участников взаимодействия выступает как дополнительный повод к социальному разрушению, и необходимо умело предотвращать возникающее по этому поводу социальное напряжение.

\section{Религия, политика и государство}

В настоящее время активно обсуждаются проблемы взаимодействия религии и политики и влияние данного союза на общественные настроения. Исследователи используют такие термины, как «религизация политики» и «политизация религии». Е.А. Терешина дает следующие определения этим понятиям: «... политизация религии - это форма проявления политической составляющей в религии». «Религизация политики в таком случае представляется полярным процессом - то есть появлением религиозных ценностей и мотивов в поле политических действий». Таким образом, это взаимное проникновение политики в религию и религии в политику (Терешина, 2012).

Рассматривая межконфессиональные отношения через призму взаимодействия государственных и религиозных институтов, следует обратить внимание на необходимость активизации самих религиозных организаций в защите своих законных интересов, в предотвращении, а в крайних случаях разрешении разного рода конфликтных ситуаций с использованием соответствующих правовых механизмов. При этом общественные и религиозные институты должны взаимодействовать друг с другом, особенно в области просветительской работы. В современных российских условиях для достижения серьезных результатов в предотвращении проявлений терроризма, экстремизма и ксенофобии необходима продуманная и целенаправленная государственная политика, которая должна охватывать все каналы социализации и формировать установки толерантного сознания и поведения в обществе. Однако сегодня в общественном мнении преобладает отрицательная оценка эффективности 
взаимодействия государственных и религиозных институтов в конкретных сферах государственной и общественной жизни, исключение составляет лишь сфера законотворчества, в которой религиозные институты выступают в качестве консультантов при принятии тех или иных правовых норм.

Главным рычагом налаживания взаимодействий между стремящимися к поиску диалога представителями разных этносов и конфессий, профилактики экстремизма является нормативная правовая и моральная поддержка со стороны государства. Основными нормативными правовыми актами, регулирующими межконфессиональные отношения в Российской Федерации на сегодняшний день, являются Конституция ${ }^{1}$, регламентирующая право каждого гражданина на свободу вероисповедания, гарантирующая равенство каждого перед законом, Федеральный закон «О свободе совести и о религиозных объединениях» ${ }^{2}$, предметом которого также выступают правоотношения в области прав человека и гражданина на свободу совести и свободу вероисповедания, а также правовое положение религиозных объединений, понятие, условия создания, регистрации и деятельности.

Законодательной базой России предусмотрено наказание за нарушение вышеназванных документов. Так, ст. 5.26 Кодекса Российской Федерации об административных правонарушениях от 30 декабря 2001 г. № 195-Ф3 (с изменениями и дополнениями $)^{3}$ закреплены меры за препятствие «осуществлению права на свободу совести и свободу вероисповедания, в том числе принятию религиозных или иных убеждений, или отказу от них, вступлению в религиозное объединение или выходу из него», осквернение религиозной литературы, а также различной атрибутики и символики в виде взыскания штрафа. Кодекс предусматривает меры наказания не только для отдельно рассматриваемых граждан, но и для религиозных организаций, занимающихся своей деятельностью с нарушением норм закона, например, за «распространение в рамках миссионерской деятельности литературы, печатных, аудио- и видеоматериалов без маркировки с указанным наименованием или с неполной либо заведомо ложной маркировкой» (ст. 5.26).

Уголовный кодекс Российской Федерации от 13 июня 1996 года № 63-Ф3 (с изменениями и дополнениями $)^{4}$ предусматривает более строгие меры наказания за нарушение права на свободу совести и вероисповеданий. Ст. 148 предполагает санкции не только в виде взыскания крупного штрафа, но и обязательные либо принудительные работы, а также лишение свободы за «публичные действия, выражающие явное неуважение к обществу и совершенные в целях оскорбления религиозных чувств верующих», «незаконное воспрепятствование деятельности религиозных органи-

\footnotetext{
1 Конституция Российской Федерации. URL: http://www.consultant.ru/document/cons_doc_ LAW_28399/.

2 Федеральный закон «О свободе совести и о религиозных объединениях». URL: http:/www. consultant.ru/document/cons_doc_LAW_16218/.

3 Кодекс Российской Федерации об административных правонарушениях: Федеральный закон от 30 декабря 2001 г. № 195-Ф3. URL: http://www.consultant.ru/document/cons_doc_LAW_34661.

4 Уголовный кодекс Российской Федерации: Федеральный закон от 13.06.1996. № 63-Ф3 URL: http:// www.consultant.ru/document/cons_doc_LAW_10699/.
} 
заций или проведению богослужений, других религиозных обрядов и церемоний». При совершении деяний, предусмотренных настоящей статьей, с использованием должностного положения, или с применением насилия, или с угрозой его применения, возможные меры наказания дополнены лишением права занимать определенные должности или заниматься определенной деятельностью на срок до двух лет. Также кодекс предусматривает ответственность за действия экстремистского характера. Федеральный закон от 25 июля 2002 г. № 114-Ф3 «О противодействии экстремистской деятельности» ${ }^{1}$ направлен на «защиту прав и свобод человека и гражданина, основ конституционного строя, обеспечения целостности и безопасности Российской Федерации, на его основе определяются правовые и организационные основы противодействия экстремистской деятельности, устанавливается ответственность за ее осуществление».

На базе основных законодательных документов и не противореча им, субъекты Российской Федерации вправе принимать на своей территории дополнительные нормативные акты в области межконфессиональных взаимодействий. Более актуально это стало после подписания Президентом РФ Федерального закона от 22 октября 2013 г. № 284-Ф3 «О внесении изменений в отдельные законодательные акты Российской Федерации в части определения полномочий и ответственности органов государственной власти субъектов Российской Федерации, органов местного самоуправления и их должностных лиц в сфере межнациональных отношений» ${ }^{2}$. В рамках данного документа пересмотрены полномочия и усилена ответственность органов власти всех уровней и их должностных лиц в сфере межнациональных отношений.

Для регулирования деятельности между религиями и конфессиями в России функционируют ведомственные подразделения разных уровней власти. При Общественной палате Российской Федерации создана Комиссия по гармонизации межнациональных и межрелигиозных отношений, работают Совет по межнациональным отношениям, Совет по взаимодействию с религиозными объединениями, главная функция которого - содействие укреплению общественного согласия, достижению взаимопонимания, терпимости и взаимного уважения в вопросах свободы совести и свободы вероисповедания, Федеральное агентство по делам национальностей (ФАДН), во многих регионах также созданы советы, деятельность которых направлена на укрепление единства и гармонизацию отношений населения в сфере межнациональных и межконфессиональных взаимодействий.

В целях реализации положений пункта 17 «Стратегии государственной национальной политики» ${ }^{3}$ об «упрочении общероссийского гражданского самосознания

\footnotetext{
1 Федеральный закон от 25 июля 2002 г. № 114-Ф3 «О противодействии экстремистской деятельности». URL: http://base.garant.ru/12127578/.

2 Федеральный закон от 22 октября 2013 г. № 284-Ф3 «О внесении изменений в отдельные законодательные акты Российской Федерации в части определения полномочий и ответственности органов государственной власти субъектов Российской Федерации, органов местного самоуправления и их должностных лиц в сфере межнациональных отношений». URL: http://base.garant.ru/70479738/.
}

3 О Стратегии государственной национальной политики Российской Федерации на период до 2025 года URL: http://www.consultant.ru/document/cons_doc_LAW_139350/. 
и духовной общности многонационального народа Российской Федерации (российской нации)»; «гармонизации национальных и межнациональных (межэтнических) отношений»; «успешной социальной и культурной адаптации и интеграции мигрантов» была разработана система государственного мониторинга этноконфессиональных отношений, в ее рамках запланировано проведение ежегодного социологического мониторинга для выявления факторов, которые вызывают напряженность на национальной или конфессиональной почве, и предупреждения на ранних этапах конфликтных ситуаций.

\section{Выводы}

Результаты изучения особенностей межнационального и межконфессионального согласия свидетельствуют о важности данного вопроса в обеспечении социальной и национальной безопасности приграничных регионов и целостности Российской Федерации.

\section{БИБЛИОГРАФИЧЕСКИЙ СПИСОК}

Баширов Л.А. Ислам в контексте этнополитических процессов в современной России. Государство, религия, церковь в России и за рубежом, 2009, No. 1, 217-227.

Беликова Е.О. Религиозная ситуация в Волгоградской области: социологический анализ, дис. ... канд. социол. наук. Волгоград, 2007.

Беликова Е.О. Поиски стратегии социологического изучения религиозной идентичности. Мониторинг общественного мнения: Экономические и социальные перемены, 2018, No. 2, 116-127.

Богатова О.А., Карьгин А.И. Мониторинг межэтнических и межконфессиональных отношений в Республике Мордовия. Финно-угорский мир, 2010, No. 1, 78-91.

Выдрина Г.А. Религиозная ситуация как объект государственного регулирования, дис. ... канд. филос. наук. М., 2004.

Денисов С.Г. Особенности религиозной ситуации и межконфессиональных отношений в современном российском мегаполисе. Социология власти, 2011, No. 4, 67-75.

Кикель П.В., Сороко Э.М. Краткий энциклопедический словарь философских терминов. Минск: БГПУ, 2008.

Кривельская Н.В. Секта: Угроза и поиск защиты. М.: Благовест, 1999.

Курачев Д.Г. Межконфессиональные отношения как формы социокультурного взаимовосприятия: Социально-философский анализ: дис. ... д-ра филос. наук. Уфа, 2005.

Лопаткин Р.А. Конфессиональный портрет России: к характеристике современной религиозной ситуации. URL: http://www.religare.ru/2_181.html.

Малашенко А.В. Исламское возрождение в современной России. М.: Моск. Центр Карнеги, 1998.

Медведко С.В. Межконфессиональные отношения как диалог культур: дис. ... канд. филос. наук. М.: РАГС, 1997. 
Мчедлов М.П., Нуруллаев А.А., Филимонов А.А., Элбакян П.С. Религия в зеркале общественного мнения. Социологические исследования, 1994, №. 5, 34-40.

Никитина А.Г. Политизация религии. Вопросы философии, 1994, №. 3, 173-180.

Нуруллаев А.А., Нуруллаев Ал.А. Религия и политика: учебное пособие. М.: КМК, 2006.

Редькина О.Ю. Старообрядцы Нижней Волги в 1917 г. Русская православная церковь и межконфессиональные отношения в Нижнем Поволжье: сб. статей. Волгоград: ВолГУ, 2003.

Рубан Л.С. Межнациональные и межконфессиональные отношения в многонациональном регионе. Религия и политика на евразийском пространстве. М., 2009, 97-103.

Сгибнева О.И. Современная религиозная ситуация: социологический анализ. Власть, 2012, №. 3, 75-78.

Синелина Ю.Ю. О циклах изменения религиозности образованной части российского общества (начало XVIII в. - 1917). Социологические исследования, 2003, No. $10,101-110$.

Сызранов А.В. Ислам в Астраханском крае: история и современность. Вестник Евразии, 2006, No. 4.

Терешина Е.А. Понятие политизации религии. Ученые записки Казанского университета. Сер. Гуманитарные науки, 2012, 154(1), 254-260.

Терещенко А.А. Политизация религии в России: современные религиозные тенденции. В кн.: Материалы круглого стола «Религия и религиоведение на Урале»: сборник научных статей и тезисов. Екатеринбург: Деловая книга, 2018, 176-178.

Трофимчук Н.А. Новые религиозные культовые движения и организации в России. М.: РАГС, 1998.

Тюгашев Н.А., Выдрина, Г.А., Попков, Ю.В. Этноконфессиональные процессы в современной Югре. Новосибирск: Нонпарель, 2004.

Хомушку O.M., Дубровский Н.Г. Религиозная ситуация и проблемы организации процесса физического и духовно-нравственного воспитания молодежи. Сибирский педагогический журнал, 2012, No. 1.

Ярулин И.Ф. Межэтнические и межконфессиональные отношения в Дальневосточном федеральном округе (по материалам социологических исследований). Хабаровск: Изд-во Тихоокеан. гос. ун-т, а, 2014.

Ярулин И.Ф., Свищев М.П., Слонский Е.С., Ярулин К.И. Динамика межэтнических и межконфессиональных отношений в Хабаровском крае. Регионалистика, 2015, № 2.

Ярыгин П. Религиозная ситуация в Волго-Вятском регионе. Социологические исследования, 1995, No. 11, 89-94.

\section{REFERENCES}

Bashirov, L. A. (2009). Islam v kontekste etnopoliticheskih protsessov v sovremennoj Rossii [Islam in the context of ethno-political processes in modern Russia]. Gosudarstvo, 
religiya, cerkov'v Rossii i za rubezhom [State, religion, Church in Russia and abroad], no $1,217-227$.

Belikova, E.O. (2007). Religioznaya situaciya v Volgogradskoyj oblasti: sociologicheskij analiz [Religious situation in the Volgograd region: sociological analysis] (PhD Thesis), Volgograd.

Belikova, E.O. (2018). Poiski strategii sociologicheskogo izucheniya religioznoj identichnosti [Searches for a strategy for the sociological study of religious identity.] Monitoring obshchestvennogo mneniya: Ekonomicheskie i social'nye peremeny [Public Opinion Monitoring: Economic and Social Change], no 2, 116-127.

Bogatova, O.A., Kar'gin, A.I. (2010). Monitoring mezhetnicheskih i mezhkonfessional'nyh otnoshenij v Respublike Mordoviya [Monitoring of interethnic and interfaith relations in the Republic of Mordovia]. Finno-ugorskiyj mir [Finno-Ugric world], no 1, 78-91.

Vydrina, G.A. (2004). Religioznaya situaciya kak ob"ekt gosudarstvennogo regulirovaniya [Religious situation as an object of state regulation] (PhD Thesis), Moscow.

Denisov, S.G. (2011). Osobennosti religioznoj situacii i mezhkonfessional'nyh otnoshenij $\mathrm{v}$ sovremennom rossijskom megapolise [Features of the religious situation and interfaith relations in the modern Russian metropolis]. Sotcologiya vlasti [Sociology of power], no 4, 67-75.

Kikel', P.V., Soroko, E.M. (2008). Kratkij enciklopedicheskij slovar'filosofskih terminov [A brief encyclopedic dictionary of philosophical terms]. Minsk: BSPU.

Krivel'skaya, N.V. (1999). Sekta: Ugroza i poisk zashchity [Sect: Threat and the search for protection]. M.: Blagovest.

Kurachev, D.G. (2005). Mezhkonfessional'nye otnosheniya kak formy sociokul'turnogo vzaimovospriyatiya: Sotsial'no-filosofskij analiz [Interfaith Relations as a Form of Sociocultural Mutual Perception: Socio-Philosophical Analysis] (PhD Thesis), Ufa.

Lopatkin, R.A. (2002). Konfessional'nyj portret Rossii: $k$ harakteristike sovremennoj religioznoj situacii [Confessional portrait of Russia: to the characteristic of the modern religious situation]. Available at: http://www.religare.ru/2_181.html

Malashenko, A.B. (1998). Islamskoe vozrozhdenie v sovremennoj Rossii [Islamic revival in modern Russia]. M.: Mosk. Centr Karnegi.

Medvedko, C.B. (1997). Mezhkonfessional'nye otnosheniya kak dialog kul'tur [Interfaith Relations as a Dialogue of Cultures] (PhD Thesis), Moscow: RAGS.

Mchedlov, M.P., Nurullaev, A.A., Filimonov, A.A., Elbakyan, P.S. (1994). Religiya v zerkale obshchestvennogo mneniya [Religion in the mirror of public opinion]. Sociologicheskie issledovaniya [Sociological studies] no 5, 34-40.

Nikitina, A.G. (1994). Politizaciya religii [The politicization of religion]. Voprosy filosofii [Philosophy Issues], no 3, 173-180.

Nurullaev, A.A., \& Nurullaev, Al.A. (2006). Religiya i politika [Religion and politics]. Moskow: KMK.

Red'kina, O.Yu. (2003). Staroobryadcy Nizhney Volgi v 1917 g. Russkaya pravoslavnaya cerkov'i mezhkonfessional'nye otnosheniya v Nizhnem Povolzh'e [Old Believers of the 
Lower Volga in 1917. The Russian Orthodox Church and interfaith relations in the Lower Volga]. Volgograd: VolGU.

Ruban, L.S. (2009). Mezhnacional'nye i mezhkonfessional'nye otnosheniya v mnogonacional'nom regione [Interethnic and interfaith relations in a multinational region]. In: Religiya i politika na evrazioskom prostranstve [Religion and politics in the Eurasian space] (pp. 97-103). Moscow.

Sgibneva, O.I. (2012). Sovremennaya religioznaya situaciya: sociologicheskij analiz [The modern religious situation: a sociological analysis]. Vlast' [Power], no 3, 75-78.

Sinelina, Yu.Yu. (2003). O ciklakh izmeneniya religioznosti obrazovannoj chasti rossijskogo obshchestva (nachalo XVIII v. - 1917) [On the cycles of religious change in the educated part of Russian society (beginning of the 18th century - 1917)]. Sociologicheskie issledovaniya [Sociological studies], no 10, 101-110.

Syzranov, A.V. (2006). Islam v Astrahanskom krae: istoriya i sovremennost' [Islam in the Astrakhan region: history and modernity]. Vestnik Evrazii [Bulletin of Eurasia], no 4.

Tereshina, E.A. (2012). Ponyatie politizacii religii [The concept of politicization of religion]. Uchenye zapiski Kazanskogo universiteta. Ser. Gumanitarnye nauki, 154(1), 254-260.

Tereshchenko, A.A. (2018). Politizaciya religii v Rossii: sovremennye religioznye tendencii [The politicization of religion in Russia: modern religious trends]. In: Materialy kruglogo stola «Religiya i religiovedenie na Urale»: sbornik nauchnyh stateo i tezisov [«Religion and religious studies in the Ural region»: the round table papers], (pp. 176178). Ekaterinburg: Delovaya kniga.

Trofimchuk, N.A. (1998). Novye religioznye kul tovye dvizheniya i organizacii v Rossii [New religious cult movements and organizations in Russia]. Moskow: RAGS.

Tyugashev, H.A., Vydrina, G.A., Popkov, Yu.V. (2004). Etnokonfessional'nye processy v sovremennoj Yugre [Ethno-religious processes in modern Ugra]. Novosibirsk: Nonparel'.

Homushku, O.M., Dubrovskij, N.G. (2012). Religioznaya situaciya i problemy organizacii processa fizicheskogo i duhovno-nravstvennogo vospitaniya molodezhi [Religious situation and problems of organizing the process of physical and spiritual-moral education of youth]. Sibirskij pedagogicheskij zhurnal [Siberian Pedagogical Journal], no 1.

Yarulin, I.F. (2014). Mezhetnicheskie i mezhkonfessional'nye otnosheniya v Dal'nevostochnom federal'nom okruge (po materialam sociologicheskih issledovanij) [Interethnic and interfaith relations in the Far Eastern Federal District (based on sociological research)]. Habarovsk: Izd-vo Tihookean. gos. un-ta.

Yarulin, I.F., Svishchev, M.P., Slonskiy, E.S., Yarulin, K.I. (2015). Dinamika mezhetnicheskih i mezhkonfessional'nyh otnoshenij v Habarovskom krae [Dynamics of interethnic and interfaith relations in the Khabarovsk Territory]. Regionalistika [Regional studies], no 2.

Yarygin, P. (1995). Religioznaya situaciya v Volgo-Vyatskom regione [Religious situation in the Volga-Vyatka region]. Sociologicheskie issledovaniya [Sociological studies], no 11, 89-94. 